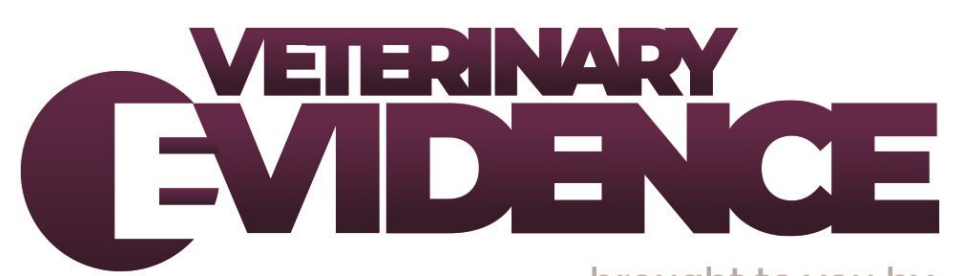

\title{
Exploring how veterinary professionals perceive and use grief support resources to support companion animal caregivers in Ontario, Canada
}

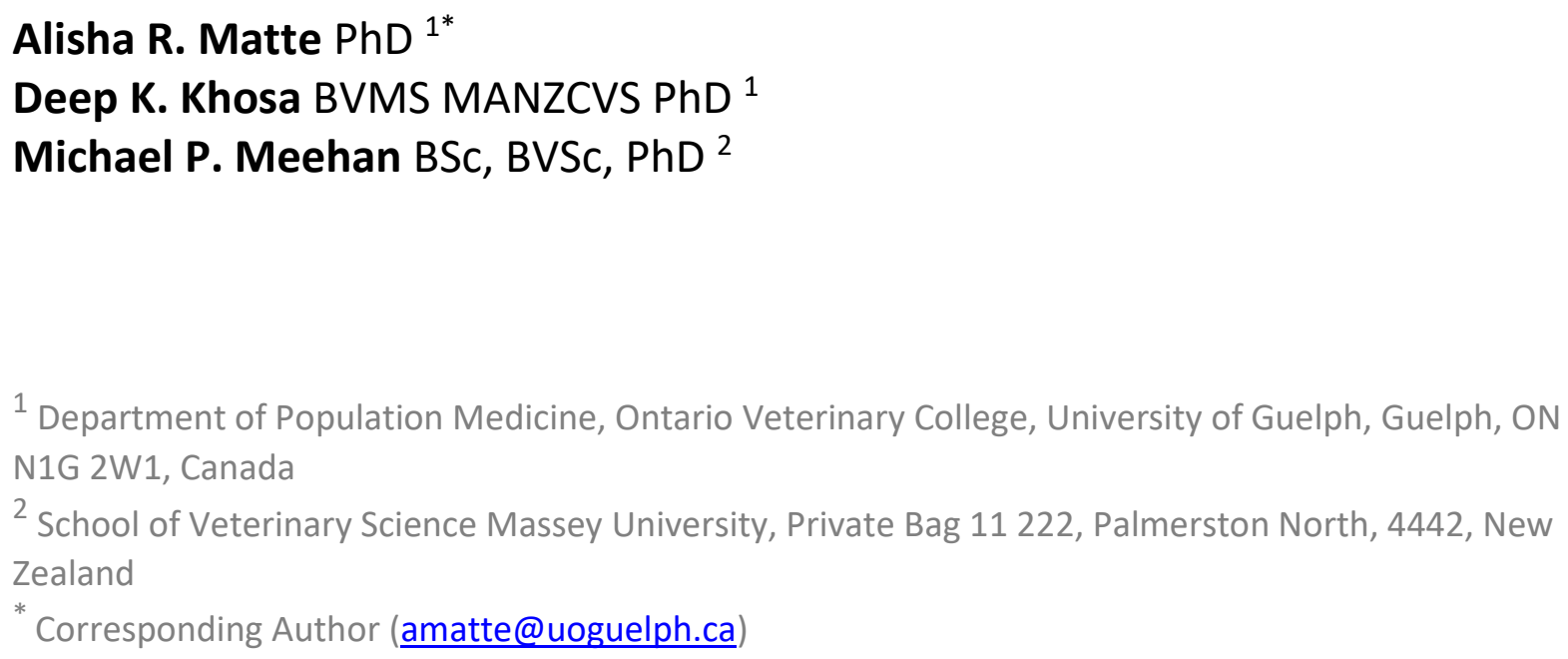

ISSN: 2396-9776

Published: 16 Dec 2021

in: The Veterinary Evidence journal Vol 6, Issue 4

DOI: https://doi.org/10.18849/ve.v6i4.430

Reviewed by: Hilary Causer (PhD) and Francesca Compostella (MSc MRCVS) 
Objective: The aim of this study was to qualitatively explore veterinary professionals' use and perceptions of grief resources and services to support companion animal caregivers following companion animal euthanasia.

Background: The loss of a companion animal can be a source of great sorrow and grief. Like human loss, many companion animal caregivers may seek out and benefit from grief resources, of which veterinary professionals are often important providers. Yet, little is known about how, when or for what reasons veterinary professionals provide these resources.

Methods: A qualitative study consisting of group and individual interviews involving 38 veterinary professionals and staff from 10 veterinary hospitals in Ontario, Canada was conducted. Verbatim transcripts were evaluated using inductive thematic analysis to identify themes and subthemes.

Results: Results indicated that typically resources were only provided if a caregiver requested information, or when veterinary professionals recognised that the caregiver may benefit from these resources. To assess a caregiver's need, participants reported considering their age, the strength of the human-animal bond, their previous and ongoing life circumstances, and their emotional state. Several barriers limiting veterinary professionals' use of grief resources were also described including perceptions that few adequate resources existed and a lack of knowledge of existing or new resources.

Conclusion: Overall, findings suggest that there are substantial opportunities to improve and embed a provision of grief resources within the veterinary profession. There is a need to develop adequate resources to meet caregivers' supportive needs and implement these resources within the greater veterinary profession.

\section{INTRODUCTION}

There are approximately 17 million companion animals (i.e., cats and dogs) in Canadian households (Canadian Animal Health Institute [CAHI], 2020). Most of these companion animals are considered to be members of the family, given familial, companion or sibling status (American Veterinary Medical Association [AVMA], 2012; CAHI, 2020; and Cohen, 2002). Due to the relatively short lifespan of companion animals compared with humans, many caregivers will experience the loss of their companion animal, if not several, in their lifetime. Most caregivers will experience significant grief symptoms following the passing of their companion animal. In some cases, these symptoms can be greater than those experienced following the loss of a human family member (Adams et al., 1999; McCutcheon \& Fleming, 2001; Planchon et al., 2002; Toray, 2004; Wrobel \& Dye, 2003; and Lavorgna \& Hutton, 2019). Unlike human loss, however, grief following the loss of a companion animal can lack social acknowledgement and support (Attig, 2004; and Meyers, 2002), placing caregivers at a greater risk for complicated and more prolonged grief experiences (Adams et al., 1999; Cordaro, 2012; and Rémillard et al., 2017). One study (Adams et al., 2000) found that nearly $30 \%$ of the 177 surveyed caregivers experienced complicated grief following the death of their companion animal, in contrast to $10-20 \%$ of a surveyed 120 individuals who experienced complicated grief following the loss of a human family member (Middleton et al., 1996).

Veterinary professionals play an important role in a caregiver's grief experience (Fernandez-Mehler et al., 2013; Hart \& Hart, 1990; Morris, 2012; and Turner, 1997). Research has found that the actions of veterinary professionals have the potential to alleviate a caregiver's grief experience or aggravate it (Adams et al., 1999; and 2000). While many veterinary professionals feel that their role in providing emotional support is important (Butler et al., 2002; Lagoni et al., 1994; and Tinga et al., 2001), many have also reported feeling unprepared and unsure as to how best to address the emotional needs of grieving caregivers following the loss of their companion animal (Adams et al., 2004; Butler et al., 2002; and Dickinson et al., 2011). Experts (Bishop et al., 2016; Lagoni et al., 1994; and Shanan, 2011) suggest that while veterinary professionals are not trained in grief 
counselling skills like psychologists and social workers, with adequate communications training, they may have the capacity to meet a degree of supportive needs. For those caregivers who may benefit or desire additional support, however, experts (Shanan et al., 2017; and Lagoni et al., 1994) agree that veterinary professionals are well-positioned to act as liaisons between them and important grief resources and services. In support of that notion, a number of Canadian veterinary organisations advise veterinary professionals to connect with and provide caregivers with access to grief-related resources and services (Bishop et al., 2016; Canadian Veterinary Medical Association [CVMA], 2014; Leary et al., 2013; and College of Veterinarians of Ontario [CVO], 2016). However, there is minimal research exploring veterinary professionals' provision of resources to support grieving clients.

Of the published research in this area, findings suggest the prevalence of veterinary professionals providing grief support resources is low (Matte et al., 2019a; 2020a; and 2020b). Yet, there was a fair interest among the public to receive access to such resources (Matte et al., 2020a; Seneca Innovation, 2020; and Dickinson et al., 2015). One study in particular (Seneca Innovation, 2020), reported that nearly half (43\%) of the 310 surveyed caregivers would have found access to community-based grief resources helpful, but only $16 \%$ of surveyed caregivers were informed of pet loss supports.

The present study seeks to gain a better understanding of how, when and for what reasons veterinary professionals use counselling services and resources for the support of caregivers experiencing companion animal loss, including veterinary professionals' perceptions of these resources.

\section{METHODS \& MATERIALS}

The study protocol was reviewed and approved by the university's Research Ethics Board (REB\#14MY006) for compliance with federal guidelines for research involving human participants.

\section{Study Design and Participants}

For the purposes of this qualitative study, grief counselling services and resources are considered to be any service or resource intended to support an individual's grief and/or bereavement experience following the loss of a companion animal and will subsequently be referred to as 'grief resources'. Resources might include written literature, documents, websites, or other materials whereas, services are performed by a trained individual such as a counsellor, support hotline, therapist or other. In the context of this study, the terms 'caregiver' and 'client' are used interchangeably replacing 'owner', with caregiver used to describe general results and client used to represent direct quotes recorded during the study.

A total of nine group and one individual interview with veterinary professionals (e.g., veterinarians, veterinary technicians, veterinary receptionists) from 10 companion animal veterinary hospitals in Wellington County, Ontario, Canada were conducted. Using a convenience sampling approach, companion animal veterinary hospitals within $25 \mathrm{~km}$ of the home research university were selected from a list collated from the College of Veterinarians of Ontario (CVO) Public Register online. The list of other eligible hospitals was randomised, and hospitals were sequentially contacted by the first author via telephone with an invitation to participate in the study. Staff from each hospital were provided with the option to participate in either a group or an individual interview format based on their availability and staff size. Participants from nine hospitals selected group discussions, and one hospital selected an individual interview format due to their smaller staff size. Participants provided written consent prior to interviews being conducted. Data collection was completed at the tenth interview when a point of theoretical saturation (Braun \& Clarke, 2006), also termed theoretical sufficiency, was achieved. Meaning an adequate depth of understanding to develop thematic meaning was achieved and no new information was being collected during the final interview (Braun \& Clarke, 2021). 


\section{Interview Structure}

All interviews took place between March and June 2016. Interviews were held at the location of the participating veterinary hospital and moderated by the first author. Interviews followed a semi-structured question guide format and consisted of open-ended questions and follow-up prompts. Notes were taken during all interviews to keep track of discussion and details of participant interactions. Demographic information was collected from all participants post-interview using a questionnaire developed by the researchers. All interviews were audio recorded and transcribed verbatim by the first author or by a professional transcriptionist. Transcripts were de-identified and quotes belonging to each participant were labelled using a sequential number-letter combination, e.g., A1 is identified as group ' $A$ ', participant \#1. Transcripts and their associated audio recordings were compared to ensure accuracy of transcription by the first author.

\section{Data Analysis}

Demographic information was analysed using descriptive statistics, including establishing means and ranges in Microsoft Excel $\AA^{\circ}$. Transcripts were imported, organised, and analysed in QSR International Pty Ltd. NVivo 12, 2018 software. To gain an in-depth understanding of veterinary professionals' perceptions and practices, an inductive thematic analysis (Braun \& Clarke, 2006) was conducted by the first author. This approach is wellsuited when there is little knowledge about a topic or when the goal is to make an in-depth exploration of the data (Merriam, 2002). Inductive thematic analysis involves 6 phases: 1) familiarisation, 2) initial coding, 3) theme identification, 4) review, 5) defining and naming themes, and 6) reporting. In brief, transcripts were read multiple times to ensure familiarisation, followed by open initial coding where code words were applied to sections of text to represent concepts participants were describing (e.g., opinions, procedures, ideas). Similar codes were then grouped into themes and associated subthemes, if applicable, and finally, defined and named. The first and second authors conducted the final step of analysis which involved a comprehensive review of all codes, themes, applicable subthemes, their attributed names, definition, and the overall relationship between the themes to establish rigor in analysis.

\section{RESULTS}

\section{Demographics}

A total of 38 participants, including veterinarians $(n=14)$, veterinary technicians $(n=9)$, veterinary assistants $(n=8)$, practice managers $(n=3)$, veterinary receptionists $(n=3)$, and client care specialists $(n=1)$ participated in interviews. The number of participants per interview ranged from 1 to 11 with an average of four participants per interview. Interview length ranged from 27.3 to 81.5 minutes, with an average of 60.2 minutes. Most participants were female $(n=33 ; 87 \%)$. The mean age of participants was 36 years (range 16-60 years) and the average number of years participants worked at their current veterinary hospital and in the veterinary profession were 3 years (range $0.5-27$ years), and 10 years (range 1-36 years), respectively.

\section{Themes}

There were two main themes related to veterinary participants' use and perceptions of grief resources and services. The first theme and its associated subthemes describe participants' use of grief resources and services for the support of bereaved caregivers. The second theme describes veterinary participants' perceptions of existing grief resources and services and their thoughts around methods of integration and use of these resources.

\section{Theme 1: Veterinary professionals assess and provide grief resources in response to caregivers' needs.}

Assessing caregivers' needs for grief resources and services - Four components were identified when participants considered a caregiver's need for professional sources of support. These components included the caregiver's age, the strength of the human-animal bond, their ongoing or previous life experiences, and the 
caregivers' emotional state. When considering the caregivers' age, one participant explained that they are often concerned for older adults stating that sometimes the companion animal, 'is all they have and that's all they live for' (E1). Secondly, participants also reported that the strength of the human-animal bond can influence a caregiver's grief severity; 'It really depends on their attachment to their pet ... they could be very attached' (E1). Thirdly, of importance was also the caregiver's current and previous life experiences with which the companion animal had been present. For example, 'if they had this pet through their high school, college, marriage, divorce years and it's been the one consistent thing' (E1), participants expressed additional concerns that the loss may lead to more severe grief. In these situations, the companion animal may act as a reminder or were important sources of support that, when lost, can complicate their grieving process. For example, in one situation described by a participant, a caregiver had recently experienced the loss of a young family member and was now facing the loss of their companion animal. In that case, the participant recognised their grief was likely to be complicated since the grief from the loss of a family member was still ongoing. Participants described recognising that they were not able to meet the caregiver's supportive needs and instead, 'they needed a psychologist' (E1).

The fourth component veterinary participants described was assessing the emotional state of the caregiver during the euthanasia procedure. Participants described doing this through empathetic practices such as visual observation, intuition, and questioning. Participants described this practice as 'putting themselves in the client's shoes.' As a participant described, 'I think it is trying to be perceptive and to read them' (A1). They also reported using questions like, 'how are you feeling?' or 'are you okay to drive home?' They described these questions as an opportunity to indirectly assess the caregiver's emotional state by, 'throw[ing] a few words out ... without verbally saying that so to speak.' (G2). Whereas when participants used questions like 'how are you feeling?' they wanted to discuss the caregiver's emotional state directly. As one participant stated;

I actually ask them how they are doing with everything because you know, you might have that strong face on but, how are you taking everything? Are you okay? They might let loose and they might, you know, keep that strong face going, but I like to ask (H11).

Some participants felt that assessing clients' emotional states can be difficult stating, 'It's very hard to judge their emotional stress' (D1) and 'sometimes, it's surprising' (E1).

Alternatively, other participants described feeling confident in their abilities, stating, 'I am pretty confident. It's like okay, trying to read their movements because sometimes they won't tell you how they are feeling. So, we kind of gotta go with their body language' (D2). While the confidence of participants varied around discussing caregivers' emotional states, all participants agreed that it is easier to interpret the emotional state of a caregiver if they have an existing relationship with them. For example, 'We have a close relationship with most of our clients, so they generally open up fairly quickly' (F7).

Grief resources offered in response to caregivers' needs - When participants did feel concerned for a caregiver's grief response, they described taking extra steps to provide support. For example, contacting the caregiver by phone or email post euthanasia, to ensure that the caregiver received additional support from the hospital. For most participants, this meant providing follow-up care after the euthanasia. For example, as a participant detailed, 'there was one client in particular. He was an older man ... He didn't have anyone to go home with. This was his last pet ... He spoke of [sic] words that made me concerned for his overall mental health and well-being' (F2). In response to this situation, the participant described ensuring that they followedup with the caregiver stating, 'I actually loaded a recall in the computer to call him the next day and make sure he was okay and if there was anything we could do' (F2).

Participants from about half of the hospitals reported having provided caregivers with information for counselling resources such as a phone number for a pet loss hotline, pamphlets, brochures, books, or virtual counselling services at some point in their veterinary career. The resources participants reported providing most often was the contact information to a pet loss hotline. 
Participants from one clinic also mentioned that they have or are aware of an individual trained in grief counselling. As a participant from one clinic described, 'I've given some [clients] the name of a technician that use [sic] to work for us. She got certified in pet loss support and counselling' (C1). In another clinic, participants mentioned that they employ a counsellor who 'follows-up with clients within 2 or 3 days, just to see how everything is going ... and offers group or individual counselling services.' (I11). To facilitate this process, participants explained that they first let caregivers know 'that we do have a counsellor calling them in a few days just to see how they are doing' (I10). At that time, caregivers can provide consent or decline the service.

\section{Theme 2: Veterinary professionals' perceptions of existing grief resources and services.}

Many participants expressed feelings of uncertainty about the adequacy of existing grief resources intended to support bereaved caregivers. Participants perceived some resources, particularly those that were Internet or telephone-based, to be difficult for caregivers to use at times; therefore, concluding that the ability of that resource to meet the supportive needs of grieving caregivers was reduced. For example, a participant described a caregiver explicitly requesting a referral to a counselling service following the loss of their companion animal. In attempting to assist the caregiver, the participant described experiencing difficulties and frustration when they were unable to find adequate resources that the caregiver felt comfortable and able to utilise;

We had to call every number we had that week to help them ... [the services] just wanted to talk to [the client] on the phone ... [but the client] said that's not helping me because [the client] was just crying on the phone (F2).

Other participants described similar opinions and feelings that many grief resources and services intended for the support of individuals experiencing companion animal loss may be insufficient due to the lack of accessible in-person supports. As a participant stated, 'I think there needs to be more available and we need to have contact numbers for these people' (H2). As this participant continued to describe;

There's too much relying on the Internet, through emails and phone calls, and all that other stuff ... These people are grieving, and they need to sit with someone and talk. They don't need to listen to you on the phone. They don't need to read an email. They need contact and there's not enough of it $(\mathrm{H} 2)$.

Participants suggested ways in which counselling resources may be improved or better managed and the possibility of partnerships with veterinary clinics. Based on their own experiences with companion animal loss counselling, participants described feeling that counselling professionals should be familiar with the veterinary profession or animal loss; either having experienced companion animal loss themselves or having professional veterinary experience. For example, one veterinary participant described their own experience following companion animal loss and the support they received from a counselling professional stating, '[the counsellor] did not have enough experience in the veterinary world ... it felt a little bit fake and a little bit pushed ... I didn't feel like [the counsellor] really understood me' (B2).

A solution suggested by participants included educating their own staff members on grief counselling and management. As a participant stated, 'I think they would be more successful if somebody who is either a technician or a vet actually has a degree in it or has extensive training' (B1). Participants felt that this was an ideal option 'because [clients] know us. A lot of them will open up more to us, talk to us and we know them better, so we can pick up little things that are going on with their grief' (B2). However, not every participant agreed with this idea. For example, as a participant explained;

I really don't think that's my place. I think I was called out to do the job and I did the job as well as I do and then I leave. My job isn't to sit there ... [and] pull stuff out of them necessarily (C1).

Many participants felt that integrating counselling professionals into large, high-volume, or specialised clinical settings was better suited. For example, as a participant explained, 'I could see it working well for a large 
hospital ... to have somebody on staff that knows how to calm people down or to talk them off the edge' (F1). Participants reported feeling this way because, 'It's a large hospital and because of that, they don't necessarily have the time to dedicate [to provide support]' (F1). As the participant continued to explain;

We are smaller, and we have the time to sit with people and that sort of thing. I also think in a large hospital you don't necessarily garner those deeper relationships that I think a smaller hospital does ...We know about their families. We know about their kids' (F1).

Participants also felt that a large hospital may have the financial ability to hire a counselling professional. Participants also saw the potential benefit of these services for their own wellbeing. As one stated, 'The reality is that euthanasia can be tough on the client, but it can also be very tough on the support staff as well' (B1), the implication being that greater access to counselling professionals within the veterinary profession might also be helpful for veterinary staff.

\section{DISCUSSION}

The following study presents insight into how veterinary professionals use and perceive grief resources intended to support caregivers following euthanasia. Veterinary participants reported most commonly providing information about grief resources when a caregiver requested it or when veterinary professionals felt that a caregiver may benefit from the additional support. Veterinary participants also identified several barriers related to their perceived suitability and knowledge of grief resources.

When considering which caregivers may benefit from additional support, participants in the present study considered several components. These included the caregiver's demographics, specifically their age, previous and on-going life experiences, the strength of the human-animal relationship and their emotional state. All these components have been shown to be associated with an individual's grief severity in previous research (Gosse \& Barnes, 1994; McCutcheon \& Fleming, 2001; and Crossley, 2013). Other components described in existing research include the circumstance of the death (i.e., expected vs. unexpected); the presence of social support (McCutcheon \& Fleming, 2001); and the caregiver's experience during companion animal euthanasia (Adams et al., 1999; 2000; and Rémillard et al., 2017). Research into the communication practices of veterinary professionals, however, has found that many of these aspects are not adequately elicited during end-of-life care discussions leading to unmet communication and supportive needs (Nogueira Borden et al., 2019; Matte et al., 2019a; and 2019b). Veterinary professionals are encouraged to reflect on these identified components of a caregiver's experience in order to better meet caregivers' supportive needs.

In the present study, veterinary participants often reported feeling that when they had an existing relationship with the caregiver, they were better able to communicate with, understand, and respond to the caregiver's grief experience and support needs. However, in many instances, veterinary professionals may not have an existing relationship. At all times, veterinary professionals need to be equipped with the appropriate communication skills to build rapport, elicit caregivers' perspectives and provide support. With an average of 15 hours devoted to training on euthanasia, communication, bereavement and analgesics in US veterinary schools (Dickinson et al., 2011), more than $75 \%$ of surveyed veterinarians $(n=463)$ reported they wished schools would place more emphasis on these communication skills and support professionals in navigating discussions with owners of terminally ill companion animals (Dickinson et al., 2015). Specifically, there is a need to provide more communication training that teaches veterinary professionals how to build a rapport, and provide support through practices such as sympathy, empathy and reassurance, to help veterinary professionals competently navigate these discussions and better meet caregivers' support needs (Nogueira Borden et al., 2019; and Shaw \& Lagoni, 2007).

In addition to communication training, recommendations based on the findings of this study conclude that consistent and sustained implementation of grief support resources can be useful in further supporting caregivers following the loss of a companion animal. In human medicine, the use of grief resources and 
support following the loss of a loved one is commonplace and includes the use of a range of socially recognised rituals such as funerals, vigils, and celebrations of life (Hudson et al., 2010), in addition to resources and services. Following companion animal loss however, many caregivers lack social support, recognition, and the option for bereavement rituals. The lack of socially recognised rituals and support can, in some cases, exacerbate grief (Meyers, 2002). By consistently providing caregivers with access to grief resources and support, veterinary professionals can assist in normalising the use of grief resources and memorialisation practices following companion animal loss. When providing supports, Dawson (2008) recommends always having this information present and accessible. For example, hospitals can have grief support information sheets, pamphlets, phone numbers, etc., displayed in the waiting room or exam rooms. Alternatively, providing a packet of information before the caregiver leaves the hospital. By doing so, caregivers can selfselect these resources.

In the present study, veterinary participants reported challenges with their ability to provide grief-related resources and referral information. Challenges included their perceptions that there were too few resources available, that they lacked awareness of existing resources and contact information, and the perception that resources were not meeting caregivers' needs for face-to-face counselling. Similar barriers have been identified in human medicine in which physicians reported a lack of available services, a lack of awareness about existing resources, a lack of shared knowledge between professionals, and the impacts of social stigma associated with seeking grief support (Ghesquiere et al., 2014; and O'Connor \& Breen, 2014). To help mitigate these barriers, there is a need to develop more reliable, accessible, and useful resources for the support of grieving caregivers and furthermore, to develop a collaborative relationship between grief resource providers and veterinary professionals. To help meet these objectives, veterinary hospitals are encouraged to seek out and connect with local, community-based, virtual and in-person supports. Through these connections, veterinary professionals can remain informed on available services, develop their own knowledge of grief resources, and even create a knowledge sharing pathway that can help to shape and inform existing resources.

\section{Limitations}

The findings of this study are drawn from the experiences and perceptions of 38 veterinary professionals working within $25 \mathrm{~km}$ of Wellington County, Ontario, Canada. Results are likely transferable to other regions which fall under the similar practice scope (small animal practice) and regulatory bodies (Smith, 2018). The use of a group interview did not appear to be a limitation of the study. All members shared and contributed to the discussion and multiple perspectives and practices were discussed. Several participants shared that these interviews were the first instance they had had the opportunity to share their perspectives and practices in a team setting. As a result, they reported learning more about how their team members approach and provide referral support to caregivers and planned to incorporate some of these new strategies into their own practices. Lastly, this study presents data that was collected in 2016, some 5 years before the time of publication. Recent studies (Matte et al., 2019a; 2019b; 2020a; and Seneca Innovation, 2020) however, have shown that the use of grief resources remains persistently limited and there is unlikely to have been significant change that would affect the validity of these results in the present day, making the outcomes and recommendations from this work relevant for present day practice.

\section{Conclusion}

This qualitative study explores veterinary professionals' use and perceptions of grief resources and services for the support of caregivers, an area of practice that is often overlooked. Given the position companion animals presently hold in society, the need for support after their loss is imperative. Veterinary professionals will continue to be an important and necessary source of grief-related support for caregivers and greater efforts are needed to support, promote and normalise this service and the use and sharing of grief-related resources following the loss of a companion animal. This will require training of specialised pet loss grief professionals, as well as greater access to a variety of grief resources and contact details provided consistently by veterinary facilities. Veterinary professionals are encouraged to routinely integrate grief and bereavement practices into their end-of-life care. Bereavement practices can include respectfully checking in with caregivers about their 
thoughts, feelings, needs, and expectations related to bereavement care and referral, offering information pamphlets and/or contact information for local grief support services. The use of follow-up methods such as condolence cards and telephone calls can also provide opportunities to connect with caregivers. The intention of these recommendations is not to overbear or overload veterinary professionals, but to support and normalise grief support practices and processes within the veterinary profession. Veterinary participants also support the idea of having a grief support steward in large clinical settings such as emergency clinics. Grief support stewards such as social workers can act as the designated individual to implement a formalised grief referral process and ensure that support information and structures are accessible sources of support for both hospital staff and caregivers coping with the loss and impacts of end-of-life care (Cordaro, 2012; and Shanan et al., 2012). It is important to not only reflect on and support the needs of the caregiver during and after companion animal euthanasia but the impacts and supportive needs of veterinary professionals too (Matte et al., 2019b).

\section{CONFLICT OF INTEREST}

The authors declare no conflicts of interest.

Acknowledgements: The authors would like to thank the participants of this study.

Funding: Research supported by a grant from the Ontario Veterinary College Pet Trust Fund.

1. Adams, C.L., Bonnett, B.N. \& Meek, A.H. (1999). Owner response to companion animal death: Development of a theory and practical implications. Canadian Veterinary Journal. 40(1), 33-39.

2. Adams, C.L., Bonnett, B.N. \& Meek, A.H. (2000). Predictors of owner response to companion animal death in 177 clients from 14 practices in Ontario. Journal of the American Veterinary Medical Association. 217(9), 1303-1309. DOI: https://doi.org/10.2460/javma.2000.217.1303

3. Adams, C.L., Conlon, P.D. \& Long, K.C. (2004). Professional and veterinary competencies: Addressing human relations and the human-animal bond in veterinary medicine. Journal of Veterinary Medical Education. 31(1), 67-72. DOI: https://doi.org/10.3138/ivme.31.1.67

4. American Veterinary Medical Association. (2012). S. Pet Ownership \& Demographics Sourcebook. American Veterinary Medical Association. [online] Available from: https://www.avma.org/sites/default/files/resources/AVMA-Pet-Demographics-ExecutiveSummary.pdf [Accessed May 2020]

5. Attig, T. (2004). Disenfranchised Grief Revisited: Discounting Hope and Love. Omega. 49(3), 197-215. DOI: https://doi.org/10.2190/P4TT-J3BF-KFDR-5JB1

6. Bishop, G., Cooney, K., Cox, S., Downing, R., Mitchener, K., Shanan, A., Soares, N., Stevens, B. \& Wynn, T. (2016). 2016 AAHA/IAAHPC End-of-Life Care Guidelines. Journal of the American Animal Hospital Association. 52(6), 341-356. DOI: https://doi.org/10.5326/jaaha-ms-6637

7. Braun, V. \& Clarke, V. (2006). Using thematic analysis in psychology. Qualitative Research in Psychology. 3(2), 77-101. DOI: https://doi.org/10.1191/1478088706qp063oa

8. Braun, V. \& Clarke, V. (2021). Conceptual and design thinking for thematic analysis. Qualitative Psychology. DOI: https://doi.apa.org/doi/10.1037/qup0000196

9. Butler, C., Williams, S. \& Koll, S. (2002). Perceptions of fourth-year veterinary students regarding emotional support of clients in veterinary practice in the veterinary college curriculum. Journal of the American Veterinary Medical Association. 221(3), 360-363.

DOI: https://doi.org/10.2460/javma.2002.221.360 
10. Canadian Animal Health Institute [CAHI]. (2019). Latest Canadian Pet Population Figures Released. [online] Available from: https://www.cahi-icsa.ca/press-releases/latest-canadian-pet-populationfigures-released [Accessed May 2020]

11. Canadian Veterinary Medical Association [CVMA]. (2014). Euthanasia - Position Statement. [online] Available from: https://www.canadianveterinarians.net/documents/euthanasia [Accessed May 2020]

12. Cohen, S.P. (2002). Can Pets Function as Family Members? Western Journal of Nursing Research. 24(6), 621-638. DOI: https://doi.org/10.1177\%2F019394502320555386

13. College of Veterinarians of Ontario [CVO]. (2016). Professional Practice Standard: Veterinary Euthanasia. [online] Available from: https://cvo.org/getmedia/62a48ea7-e4ff-4462-a28fafe2fde9bbd2/PPSVeterinaryEuthanasia.pdf.aspx [Accessed May 2020]

14. Cordaro, M. (2012). Pet Loss and Disenfranchised Grief: Implications for Mental Health Counseling Practice. Journal of Mental Health Counselling. 34(4), 283-294.

DOI: https://doi.org/10.17744/mehc.34.4.41q0248450t98072

15. Crossley, M.K. (2013). Pet Loss and Human Bereavement: A Phenomenological Study of Attachment and the Grieving Process. [Doctoral Dissertation, University of Toronto]. NC State Repository. [online] Available

from: https://repository.lib.ncsu.edu/bitstream/handle/1840.16/8451/etd.pdf?sequence=2\&isAllowe $\mathrm{d}=\mathrm{y}$ [Accessed May 2020]

16. Dawson, S. (2008). Continuing Care Clinics: A new concept in pet loss support. Veterinary Nursing Journal. 23(9), 39-41. DOI: https://doi.org/10.1080/17415349.2008.11013729

17. Dickinson, G.E., Roof, P.D. \& Roof, K.W. (2011). A Survey of Veterinarians in the US: Euthanasia and Other End-of-Life Issues. Anthrozoös. 24(2), 167-174.

DOI: https://doi.org/10.2752/175303711X12998632257666

18. Dickinson, G.E. \& Paul, E.S. (2015). End-of-life issues in UK medical schools. American Journal of Hospice and Palliative Medicine ${ }^{\circledR} .32(6), 634-640$. DOI: https://doi.org/10.1177/1049909114530492

19. Fernandez-Mehler, P., Gloor, P., Sager, E., Lewis, F.I. \& Glaus, T.M. (2013). Veterinarians' role for pet owners facing pet loss. Veterinary Record. 172(21), 555. DOI: http://dx.doi.org/10.1136/vr.101154

20. Ghesquiere, A.R., Patel, S.R., Kaplan, D.B. \& Bruce, M.L. (2014). Primary care providers' bereavement care practices: recommendations for research directions. International Journal of Geriatric Psychiatry. 29(12), 1221-1229. DOI: https://doi.org/10.1002/gps.4157

21. Gosse, G.H. \& Barnes, M.J. (1994). Human Grief Resulting from the Death of a Pet. Anthrozoös. 7(2), 103-112. DOI: https://doi.org/10.2752/089279394787001970

22. Hart, L. \& Hart, B.L. (1990). Humane euthanasia and companion animal death: caring for the animal, the client and the veterinarian. Journal of the American Veterinary Medical Association. 197(10), 1292-1299.

23. Hudson, P.L., Remedios, C. \& Thomas, K. (2010). A systematic review of psychosocial interventions for family carers of palliative care patients. BMC Palliat Care. 9, 17. DOI: https://doi.org/10.1186/1472$\underline{684 X-9-17}$

24. Lagoni, L., Butler, C. \& Hetts, S. (1994). The human-animal bond and grief. Philadelphia: WV Saunders Company.

25. Lavorgna, B.F. \& Hutton, V.E. (2019). Grief severity: A comparison between human and companion animal death. Death Studies. 43(8), 521-526. DOI: https://doi.org/10.1080/07481187.2018.1491485

26. Leary, S., Underwood, W., Anthony, R., Cartner, S., Corey, D., Grandin, T., Greenacre, C., GwaltneyBrant, S., McCrackin, M.A., Meyer, R., Miller, D., Shearer, J. \& Yanong, R. (2013). AVMA Guidelines for the Euthanasia of Animals: 2013 Edition. Schaumburg, IL: American Veterinary Medical Association. [online] Available from: https://www.avma.org/sites/default/files/resources/euthanasia.pdf [Accessed May 2020]

27. Matte, A.R., Khosa, D.K., Coe, J.B. \& Meehan, M.P. (2019a). Impacts of the process and decisionmaking around companion animal euthanasia on veterinary wellbeing. Veterinary Record. 185(15), 480. DOI: https://doi.org/10.1136/vr.105540 
28. Matte, A.R., Khosa, D.K., Meehan, M.P., Coe, J.B. \& Niel, L. (2019b). An Exploratory Study of Veterinary Professionals' Self-Reported Support of Bereaved Clients Before, During, and After Companion Animal Euthanasia in Southwestern Ontario, Canada. OMEGA - Journal of Death and Dying. 83(3), 352-370. DOI: https://doi.org/10.1177/0030222819853924

29. Matte, A.R., Khosa, D.K., Coe, J.B., Meehan, M. \& Niel, L. (2020a). Exploring pet owners' experiences and self-reported satisfaction and grief following companion animal euthanasia. Veterinary Record. 187(12), e122. DOI: https://doi.org/10.1136/vr.105734

30. Matte, A.R., Khosa, D.K., Coe, J.B., Meehan, M. \& Niel, L. (2020b). Exploring veterinarians' use of practices aimed at understanding and providing emotional support to clients during companion animal euthanasia in Ontario, Canada. Veterinary Record. 187(9), e74.

DOI: https://doi.org/10.1136/vr.105659

31. McCutcheon, K.A. \& Fleming, S.J. (2001). Grief Resulting from Euthanasia and Natural Death of Companion Animals. OMEGA - Journal of Death and Dying. 44(2), 169-188.

DOI: https://doi.org/10.2190/5QG0-HVH8-JEDO-ML16

32. Merriam, S.B. (2002). Introduction to qualitative research. Qualitative research in practice: Examples for discussion and analysis. 1(1), 1-17.

33. Meyers, B. (2002). Disenfranchised grief and the loss of an animal companion. In: Doka, K.J. ed., Disenfranchised grief: New directions, challenges, and strategies for practice. Champaign, IL: Research Press, 251-264.

34. Middleton, W., Burnett, P., Raphael, B. \& Martinek, N. (1996). The Bereavement Response: A Cluster Analysis. British Journal of Psychiatry. 169(2), 167-171. DOI: https://doi.org/10.1192/bjp.169.2.167

35. Morris, P. (2012). Euthanasia in Veterinary Medicine. In: Blue Juice: Euthanasia in Veterinary Medicine. Philadelphia, PA: Temple University Press, 1-18.

36. Nogueira Borden, L.J., Adams, C.L., Bonnett, B.N., Ribble, C.S. \& Shaw, J.R. (2019). Comparison of veterinarian and standardized client perceptions of communication during euthanasia discussions. Journal of the American Veterinary Medical Association. 254(9), 1073-1085. DOI: http://dx.doi.org/10.2460/javma.254.9.1073

37. Rémillard, L.W., Meehan, M.P., Kelton, D.F. \& Coe, J.B. (2017). Exploring the Grief Experience Among Callers to a Pet Loss Support Hotline. Anthrozoös. 30(1), 149-61.

DOI: https://doi.org/10.1080/08927936.2017.1270600

38. Seneca Innovation. (2020). Pet Loss Best Practice Guidelines: For Veterinary Teams. 1-48. [online] Available from: https://www.senecacollege.ca/content/dam/projects/seneca/schools/school-ofhealth-science/final-report-pet-loss-best-practice-guidelines-for-veterinary-teams.pdf [Accessed May 2020]

39. Shanan, A. (2011). A Veterinarian's Role in Helping Pet Owners with Decision Making. Veterinary Clinics of North America: Small Animal Practice. 41(3), 635-646.

DOI: https://doi.org/10.1016/i.cvsm.2011.03.006

40. Shanan, A., Pierce, J. \& Shearer, T. (2017). Hospice and Palliative Care for Companion Animals: Principles and Practice. New York: John Wiley \& Sons. DOI: https://doi.org/1002/9781119036722

41. Smith, B. (2018). Generalizability in qualitative research: misunderstandings, opportunities and recommendations for the sport and exercise sciences. Qualitative Research in Sport, Exercise and Health. 10(1), 137-149. DOI: https://doi.org/10.1080/2159676X.2017.1393221

42. Tinga, C.E., Adams, C.L., Bonnett, B.N. \& Ribble, C.S. (2001). Survey of veterinary technical and professional skills in students and recent graduates of a veterinary college. Journal of the American Veterinary Medical Association. 219(7), 924-931. DOI: https://doi.org/10.2460/javma.2001.219.924

43. Toray, T. (2004). The Human-Animal Bond and Loss: Providing Support for Grieving Clients. Journal of Mental Health Counseling. 26(3), 244-259.

DOI: https://doi.org/10.17744/mehc.26.3.udj040fw2gj75lap

44. Turner, W.G. (1997). Evaluation of a Pet Loss Support Hotline. Anthrozoös. 10(4), 225-230.

DOI: https://doi.org/10.2752/089279397787000914 
45. Wrobel, T.A. \& Dye, A.L. (2003). Grieving Pet Death: Normative, Gender, and Attachement Issues. OMEGA - Journal of Death and Dying. 47(4), 385-393. DOI: https://doi.org/10.2190/QYV5-LL1$\underline{\text { T043-UOF9 }}$ 


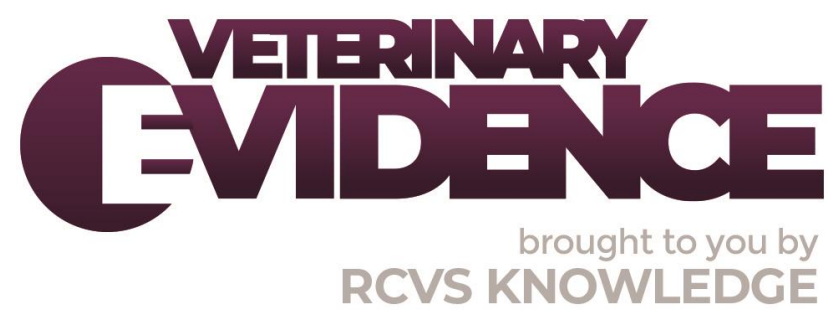

\section{Intellectual Property Rights}

Authors of Knowledge Summaries submitted to RCVS Knowledge for publication will retain copyright in their work, and will be required to grant RCVS Knowledge a non-exclusive license of the rights of copyright in the materials including but not limited to the right to publish, re-

publish, transmit, sell, distribute and otherwise use the materials in all languages and all media throughout the world, and to license or permit others to do so.

\section{Disclaimer}

Any opinions expressed in articles and other publication types published in Veterinary Evidence are the author's own and do not necessarily reflect the view of the RCVS Knowledge. Veterinary Evidence is a resource to help inform, and the content herein should not override the responsibility of the practitioner. Practitioners should also consider factors such as individual clinical expertise and judgement along with patient's circumstances and owners' values. Authors are responsible for the accuracy of the content. While the Editor and Publisher believe that all content herein are in accord with current recommendations and practice at the time of publication, they accept no legal responsibility for any errors or omissions, and make no warranty, express or implied, with respect to material contained within.

For further information please refer to our Terms of Use.

RCVS Knowledge is the independent charity associated with the Royal College of Veterinary Surgeons (RCVS). Our ambition is to become a global intermediary for evidence based veterinary knowledge by providing access to information that is of immediate value to practicing veterinary professionals and directly contributes to evidence based clinical decision-making.

https://www.veterinaryevidence.org/

RCVS Knowledge is a registered Charity No. 230886.

Registered as a Company limited by guarantee in England and Wales No. 598443.

Registered Office: Belgravia House, 62-64 Horseferry Road, London SW1P 2AF

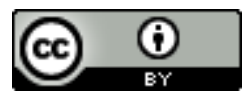

This work is licensed under a Creative Commons Attribution 4.0 International License. 